\author{
МИХАИЛ ПАВЛОВЕЦ \\ Национальный исследовательский университет \\ «Высшая школа экономики» \\ Факультет гуманитарных наук \\ Школа филологии \\ 101000, г. Москва, \\ ул. Мясницкая, д. 20 \\ pavlovez@mail.ru
}

\title{
СОВЕТСКАЯ ПОЭЗИЯ В 1926 ГОДУ В ЗЕРКАЛЕ АНКЕТИРОВАНИЯ ПИСАТЕЛЕЙ И ЧИТАТЕЛЕЙ
}

\author{
SOVIET POETRY IN 1926 IN THE LIGHT OF \\ WRITERS' AND READERS' OPINION SURVEYS
}

В статье рассматривается проблема востребованности поэзии в СССР на примере всего одного - 1926 года, когда одновременно несколько литературных изданий решило исследовать отношение к ней читателей и самих поэтов. Анализ проведенных опросов читателей и библиотек показывает правоту Бориса Пастернака, который утверждал, что в настоящее время лирическая поэзия переживает кризис, связанный с утратой прежнего ее адресата и несформированности нового реципиента, который бы нуждался в лирических формах презентации субъектности ее автора.

Ключевые слова: поэзия, лирика, Борис Пастернак, рецепция, читатель.

The article researches the issue of the relevance of poetry in the USSR, using as an example the year 1926, when several literary periodicals simultaneously decided to investigate the attitude of their readers and of poets towards this issue. The analysis of the surveys conducted among readers and in libraries confirms the statement made by Boris Pasternak that lyric poetry was then undergoing a crisis, caused by the loss of its past audience and by not yet having any new audience who would need the subjectivity of an author to be presented to them in a lyrical form.

Keywords: poetry, lyric poetry, Boris Pasternak, reception, reader, audience.

Одно из самых известных высказываний Бориса Пастернака о современной ему отечественной поэзии - ответ на анкету «Ленинградской правды», датированный 18 января 1926 года. 20 января Л. В. Горнунг записал в дневнике: 
Борис Леонидович рассказал мне, что ему прислали из редакции «Ленинградской правды» анкету с вопросами о положении современной поэзии. Эта анкета рассылалась литераторам Москвы и Ленинграда. Он сказал, что относится к ней несерьезно и ответил на вопросы иронически ${ }^{1}$.

В газете текст ответов Бориса Пастернака так и не появился и впервые был опубликован в журнале «Звезда», в № 2 за 1990 год по машинописи, сохранившейся в архиве A. Е. Крученых ${ }^{2}$, а затем повторен в IV томе пятитомного собрания сочинений писателя ${ }^{3}$ с ошибочным указанием: «Ответы на вопросы анкеты публиковались в январе 1926 года» 4 У нас даже нет самих вопросов анкеты: впрочем, о первом из них можно косвенно догадаться по началу ответа Пастернака:

Вы говорите, что стихов писать не перестали, хотя их не печатают, изданных же не читают. Ценное наблюдение, хотя не оно меня убеждает в упадке поэзии $[\ldots]^{5}$.

Остальные вопросы непосредственно включены в текст поэта и при издании в Полном собрании его сочинений были выделены курсивом:

Кто виноват в бедственном положении поэзии? [...]

Можно ли тут чем-нибудь помочь? [...]

Нужна ли вообще поэзия? ${ }^{6}$

Вызывает некоторое удивление желание газеты «Ленинградская правда» - печатного органа Ленинградского комитета РКП(б) - провести такого рода опрос среди действующих писателей, так как в целом материалы, посвященные литературе и другим видам искусства, занимают крайне незначительное место среди прочих публикаций издания. Страницы «Ленинградской правды» в 1926 году изобилуют речами и отчетами партийных деятелей, а также новостями с фронта борьбы с троцкистской оппозицией. Так, «поэзия» представлена главным образом довольно беспомощными пропагандистскими стихотворениями Владимира Соловьева (впоследствии - популярного драматурга), пролетарских поэтов Ивана Логинова и Василия Казина, а также Демьяна Бедного; кроме того, 19 мая был опубликован под заголовком $O$ работе поэта отрывок очерка В. Маяковского Как делать стихи. Никаких следов

1 Л. Горнунг, Встреча за встречей. По дневниковым записям, [в:] Б. Пастернак, Полное собрание сочинений с приложениями: в 11-ти томах, Том XI: Борис Пастернак в воспоминаниях современников, Москва: «Слово»/«Slovo» 2005, с. 75.

${ }^{2}$ РГАЛИ, 1334.1.25.

${ }^{3}$ Б. Пастернак, Ответ на анкету «Ленинградской правды»", [в:] он же, Собрание сочинений в пяти томах, Москва: «Художественная литература» 1991, т. IV, с. 619-620.

${ }^{4}$ Там же, с. 877.

${ }^{5}$ Б. Пастернак, Ответ на анкету «Ленинградской правды»», [в:] он же, Полное собрание сочинений с приложениями: в 11-ти томах, Москва: «Слово»/«Slovo», т. V, с. 214.

${ }^{6}$ Там же, с. $214-215$. 
попытки обнародовать результаты опроса современных авторов в газете 1926 года нами не обнаружено, только 16 мая редакция обратилась к своим читателям с просьбой:

1) Присылать отзывы (краткие или подробные) о прочитанных литературно-художественных произведениях, русских или иностранных.

2) Сообщать, какой вид художественных произведений предпочитаете другим, кто больше из писателей нравится - современные или старые, русские или иностранные, выделяете ли пролетарских писателей или не замечаете такой разницы.

3) Что дает вам художественная литература (отдых, знания, сильные ощущения и т.п. $)^{7}$ (с. 4$)$.

Однако данные вопросы касались восприятия литературы в целом, а не только поэзии и не только современной. Единственным материалом, который может быть воспринят как попытка анализа современного состояния советской поэзии, является статья Николая Асеева Советская поэзия в 1926 году, опубликованная в номере за 28 ноября ${ }^{8}$. Несмотря на то что формально Пастернак и Асеев все еще были «в одном лагере» (в ЛЕФе), их позиции по отношению к современной поэзии во многом оказались противоположны.

Избегая называть чьи-либо имена, Пастернак солидаризируется с заключенной в вопросе констатацией факта упадка современной поэзии, замечая:

[...] мы пишем крупные вещи, тянемся в эпос, а это определенно жанр второй руки. Стихи не заражают больше воздуха, каковы бы ни были их достоинства. Разносящей средой звучания была личность. Старая личность разрушилась, новая не сформировалась. Без резонанса лирика немыслима.

Короче говоря, с поэзией обстоит дело преплачевно ${ }^{9}$.

Мысль о том, что современная эпоха чужда лирике и востребует поиски в области эпического, одна из постоянных для Пастернака в данное время ${ }^{10}$ : в том же, 1926 году, отвечая на вопрос журнала «На литературном посту» «Над чем работают писатели», он объясняет причины,

7 «Ленинградская правда» 1926, 16 мая, с. 4.

${ }^{8}$ Н. Асеев, Советская поэзия в 1926 году, «Ленинградская правда» 1926, 28 ноября, с. 5.

${ }^{9}$ Б. Пастернак, Ответ на анкету..., с. 214.

${ }^{10}$ Напомним, за два года до Пастернака об этом заявил в статье Промежуток (1924) Юрий Тынянов, возводивший конец поэтической эпохи к закату «кафейного периода» (Валерий Брюсов) русской литературы и определивший наступившее для поэзии «безвременье» как период «промежутка»: «Три года назад проза решительно приказала поэзии очистить помещение. [...] Все мы отчетливо видели: проза побеждает, поэзия отступает, все мы даже почему-то радовались этому (очень уж приелись вечера поэтов), но, собственно, в чем дело, что из этой победы выйдет и куда это окончательно отступит поэзия, - так как-то ближайшим образом и не представляли. Теперь - поэзия «отступила» окончательно, и дело оказывается не очень простым» (Ю. Тынянов, Промежуток, [в:] он же, Литературный факт, Москва: «Высшая школа» 1993, с. 264-265). 
заставившие обратиться его к крупным формам: «В наше время лирика почти перестала звучать, и здесь мне приходится быть объективным, от лирики переходить к эпосу» ${ }^{11}$. Обоснование этой позиции мы находим в ответах на анкету «Ленинградской правды»: Пастернак поясняет, что любое обновление в лирике связано с обновлением как лирического субъекта, так и читателя-реципиента, причем смена антропологической модели обусловлена переходным характером наступившей эпохи, когда в прошлое уходит прежняя культура, а на ее месте возникает новая, требующая своего осмысления. Современная эпоха характеризуется Пастернаком как

период до крайности условный, развивающийся в постоянном расчете на нового человека, в расчете, прибавим, который и сам болеет и видоизменяется и из агитационного лозунга дня становится вольным двигателем поколения ${ }^{12}$.

Причем сам поэт предлагает осмыслять этот процесс как разрыв, пресечение традиций, не довольствуясь мнением, что «искусство нужно для сохранения преемственности, как перемет от старой к новой, будущей культуре», апеллируя при этом... к природе, которой, по его словам, «легче бороться с внезапным препятствием, нежели с постоянным тормозом, задрапированным формами потворства» ${ }^{13}$. Такая натурализация культурных процессов - вполне в духе Пастернака, убежденного, что ни новая личность, ни новая поэзия не могут быть сконструированы искусственно, путем социального или культурного моделирования, но должны возникнуть в свое время, органично. («Можно ли тут чемнибудь помочь? Только средствами черной магии» $\left.{ }^{14}\right)$. По этой же причине сомнителен и «конец поэзии», так как она является производным от личности и истории, а потому просто не может исчезнуть окончательно.

Иной путь разговора о судьбах современной поэзии выбирает Николай Асеев, причем, судя по всему, он вряд ли опирался в своих рассуждениях на вопросы анкеты. По сути статья-обзор Асеева - попытка «отделить овец от козлищ»: перспективные, с точки зрения автора, тенденции в советской поэзии от деструктивных. И здесь показательно, что он начинает свою статью с имени Сергея Есенина:

Заканчивающийся год в нашей поэзии прошел под знаком трагически неожиданного конца Сергея Есенина. [...] Между тем у С. Есенина есть всего лишь два-три десятка первоклассных стихотворений, сделавших ему известность, за которыми в полном собрании сочинений вскрываются залежи неотделанных, наивных стихов.

11 «На литературном посту» 1926, № 1, с. 51. В дальнейшем ссылка на подшивку этого журнала за 1926 год будет даваться в тексте с указанием номера издания и страницы цитирования.

${ }^{12}$ Б. Пастернак, Ответ на анкету..., с. 214.

${ }^{13}$ Там же.

14 Там же. 
Чем же объяснить помимо гипнотизирующего своей трагичностью конца - влияние С. Есенина на современность? Мне кажется, оно объясняется некоторой долей общей пониженности требований к стиху, которая вместе с зачатками истеричности, нервной надорванности и примитивизма ощущений - толкает читателя к песенной эмоциональности, к надрыву, к неуравновешенности ощущений, так полно отразившихся в стихах С. Есенина ${ }^{15}$.

Таким образом, Асеев включается в борьбу с «есенинщиной», начатой его товарищем по Левому Фронту Владимиром Маяковским в его стихотворении Сергею Есенину, видя в следовании Есенину главную опасность для современной поэзии. Показательно, что стихотворение Маяковского - единственное этого поэта за год! - также печатается в «Ленинградской правде», как и фрагмент из статьи Как делать сти$x u^{16}$ - не тот, впрочем, который посвящен полемике автора с Есениным, где, в частности, он пишет:

Осматривая со всех сторон эту смерть и перетряхивая чужой материал, я сформулировал и поставил себе задачу. Целевая установка: обдуманно парализовать действие последних есенинских стихов, сделать есенинский конец неинтересным, выставить вместо легкой красивости смерти другую красоту, так как все силы нужны рабочему человечеству для начатой революции, и оно, несмотря на тяжесть пути, на тяжелые контрасты нэпа, требует, чтобы мы славили радость жизни, веселье труднейшего марша в коммунизм ${ }^{17}$.

Таким образом, и Маяковский, и Асеев не случайно встретились на страницах главной партийной газеты Ленинграда - города, где не так давно покончил с собой Сергей Есенин. Причем характерно, что если Маяковский вел полемику с жизненной позицией этого поэта (какой она ему представлялась), то Асеев перешел в наступление на позиции противников по литературному полю, а именно - подвергнув критике творчество так называемых «комсомольских поэтов». В творчестве своих антагонистов Н. Асеев усмотрел стороны если не родственные Есенину, то прямо подталкивающие современную молодежь к «есенинщине»:

Кроме всего этого, хорошую почву для восприятия есенинской лирики создали большинство из комсомольских поэтов. Таковы, например, Безыменский, Жаров, Уткин и др. Вялость, небрежность, неотделанность их стихов, нравоучительность, официальный оптимизм их тем отталкивает внимание читателей от стихов вообще ${ }^{18}$.

Эта полемика - одно из проявлений известного противостояния ЛЕФа с РАПП и близкими ей «комсомольскими поэтами», причем, чтобы скрыть «групповой» характер конфликта, Асеев выделяет из молодой

${ }^{15}$ Н. Асеев, Поэзия в 1926 году, «Ленинградская правда» 1926, 28 ноября, с. 5.

16 В. Маяковский, Сергею Есенину. Как делать стихи, «Ленинградская правда» 1926, 23 мая, с. 3.

17 В. Маяковский, Как делать стихи?, [в:] он же, Сочинения в двух томах, Т. 2. Поэмы. Пьесы. Проза, Москва: «Правда» 1988, с. 679.

${ }^{18}$ Н. Асеев, Поэзия в 1926 году.., с. 5. 
поросли поэтов М. Светлова, М. Голодного и В. Саянова - авторов, чьи имена также обычно упоминаются в контексте «комсомольской поэзии» ${ }^{19}$. В целом же вывод Асеева о состоянии современной ему поэзии - прямо противоположен пастернаковскому:

Если прибавить к этому, что за этот же год были опубликованы ими такие вещи, как Товарищу Нетте и Письмо к Горькому Маяковского, Лейтенант Шмидт Б. Пастернака, Улялаевщина Сельвинского, его же Рекорды, целый ряд стихов Николая Тихонова и С. Кирсанова, думается, что ни у одной страны нет такого запаса свежести, ясности и богатства мелодий, каким обладает сейчас советское современье $\mathrm{e}^{20}$.

Этот «бодряческий» тон, тем не менее, не означает, что Асеев не признавал наличия некоторого кризиса в поэзии: всего лишь за месяц до этого на страницах журнала «Новый мир» он выступил с обзором современной поэзии Новые песни, в котором, в частности, замечал:

Количество стихов, еще недавно пугавшие [sic! - M. П.] редакции и издательства и вызывавшие с их стороны суровые заградительные меры, заметно уменьшилось. Помогли ли здесь эти самые меры, меньше ли стали писать стихов или же их труднее стало печатать - вопрос, не решенный теоретически, но на рынке, на прилавках магазинов, на витринах стихам стали отводить весьма скромное место. В соответствии с этим медленно начал выравниваться тот общий, средний уровень квалификации поэтической работы, недостаток которого у одних группировок и избыток у других создавали впечатление крайней оторванности, отдаленности этих группировок, в одной своей части владевших всеми идеологическими, в другой - всеми формальными преимуществами. Сближение их может произойти лишь под влиянием критико-общественного нажима ${ }^{21}$.

Действительно, еще несколько лет назад в литературной прессе остро обсуждался вопрос о засилии в советской поэзии низкопробной, графоманской стихотворной продукции, избыток которой Осип Мандельштам объяснял в очерке Армия поэтов: 1. И их сотни тысяя (опубликованном в № 33 журнала «Огонек» за 1923 году) массовым неврозом первых послереволюционных лет:

После тяжелых переходных лет количество пишущих стихи сильно увеличилось. На почве массового недоедания увеличилось число людей, у которых интеллектуальное возбуждение носит болезненный характер и не находит себе выхода ни в какой здоровой деятельности ${ }^{22}$.

${ }^{19}$ Впрочем, Асеев в то время особенно благоволил упомянутым авторам: он принимал участие в заседании ленинградского литературного кружка «Смена», возглавляемого В. Саяновым, и откликнулся благожелательной рецензией на выход его первого сборника Фартовые года (см.: Н. Асеев, Виссарион Саянов («Фартовые года», 1926), «Печать и революция» 1926, № 4, с. 202-203). Писал он и о Михаиле Светлове (рецензия на книгу 1927 года: Н. Асеев, Михаил Светлов («Ночные встречи», 1927), «На литературном посту» 1927 , № 10, с. $27-31)$.

${ }^{20} \mathrm{H}$. Асеев, Поэзия в 1926 году..., с. 5.

${ }^{21}$ Н. Асеев, Новые песни, «Новый мир» 1926, № 10, с. 150-158.

${ }^{22}$ О. Мандельштам, Армия поэтов, [в:] он же, Собрание сочинений в 4-х томах, Т. 2. Проза, Москва: TEPPA - TERRA 1991, с. 210. Через год на ту же тему высказался и Эмилий Миндлин в статье 8000 поэтов в СССР («Вечерняя Москва» 1924, 8 апреля): статья 
Однако уменышение количества пишущих и, главное, печатающих стихи вовсе не привело к увеличению числа их читающих, и этого не мог не почувствовать Николай Асеев. Его попытка объяснить падение интереса к лирике «дурным влиянием» есенинщины или низким уровнем «комсомольской поэзии» явно было неслучайным: анкетирование массового читателя, в том числе и довольно-таки образованных его представителей, показывало, что на слуху у читателей были как раз имена Есенина и «комсомольских поэтов», а вовсе не тех, кого пытался продвигать Н. Асеев.

Об этом можно судить по анкете, запущенной в том же 1926 году редакцией журнала «На литературном посту». В № 1 под рубрикой «Наша анкета» сообщалось:

Мы обратились к ряду виднейших партийных и советских работников, к представителям научной мысли Советского Союза, а также к широким читательским массам, представителям партийных ячеек и фабзавкомов крупнейших промышленных предприятий нашего союза с анкетой:

1. Читаете ли Вы современную русскую литературу?

2. Какое из произведений современной русской литературы последнего времени Вам больше всего нравится?

3. Чем Вас современная литература не удовлетворяет?

4. Чего бы Вы хотели от современной русской литературы?

C настоящего номера мы начинаем печатать полученные нами ответы, после чего мы дадим в журнале ответы писателей по поводу анкеты.

Редакичия (1:50-51)

Ответы как «виднейших партийных и советских работников», так и «представителей научной мысли Советского Союза» отличаются почти полным отсутствием в них упоминаний поэзии и еще больше тем, что среди все-таки упомянутых поэтов почти нет тех, чье творчество пережило свое время. Так, упоминаются: Мари буденовцев (песня); Комсомолия А. Безыменского (1:50) (Юрий Ларин, деятель революционного движения и тесть Н. Бухарина); «стихи Демьяна Бедного, Безыменского, кое-что Жарова и др.» (2:34) («т. Титов, Секретарь ячейки ВПК(б) машиностроительного завода имени Владимира Ильича»); «Безыменский, Жаров» (5/6:59) («т. Шапаров, Председатель фабкома форменного отделения 2-й фабрики Госзнака»); «Груз Безыменского и кое-что Бедного» (5/6:59) («красноармеец Александров»). Остальные опрошенные, среди которых такие видные фигуры, как М. Павлович (ректор Института востоковедения), В. Кнорин (Зав. Агитпропа ЦК ВКП (б)); Д. Курский (народный комиссар юстиции и прокурор РСФСР); М. Литвинов (зам. наркома иностранных дел); А. В. Луначарский (народный комиссар

вынудила редакцию газеты обратиться к ряду поэтов с просьбой высказать свое отношение к деятельности СОПО - Союза поэтов, среди членов которого оказалось немало графоманов. Наряду с В. Маяковским, Д. Бедным и другими, отрицательно оценил уровень авторов СОПО и Н. Асеев (см.: «Вечерняя Москва» 1924, 10 апреля). 
просвещения) и др. предпочли говорить о прозе или вовсе сослаться на свою загруженность, мешающую читать книги.

Столь же удручающую картину с чтением поэзии дают и опросы работников библиотек. Писатель-рапповец А. Исбах в очерке Что читает коломенский рабочий сообщает, что «много читают НовиковаПрибоя и Демьяна Бедного» (1:50), из поэтов предпочтение выказывается «классикам» - Некрасову и Никитину, кроме того, «читают Безыменского, Есенина, Маяковского, Жарова, Доронина. Но в массе поэтов мало знают» (1:51). Библиотека Клуба им. Жилина при объединенном клубе кожевников и металлистов сообщает редакции журнала, что «среди молодежи есть интерес и к поэзии», но при этом уточняется: «Читают Пушкина, Никитина, Лермонтова, Есенина. Читают их потому, что новая поэзия читателей не удовлетворяет» (3:57) - здесь обращает на себя внимание, что Есенин, скорее всего невольно, был вычеркнут из «новой поэзии», замкнув собой ряд поэтов-«классиков». Сотрудники библиотеки клуба им. Бундурина при ситценабивной фабрике (бывш. Циндель) свидетельствовали: «Рабочая молодежь проявляет большой интерес к [...] Безыменскому (Комсомолия), Есенину [...] Из современных поэтов читают Безыменского и Жарова, Демьяна Бедного не читают совсем (3:57)». Библиотека 1-й образцовой типографии (бывшей Сытина), напротив, опровергает факт большого интереса рабочей молодежи к поэзии; и здесь - те же имена: «Интерес к поэзии среди молодежи очень невелик. Читают больше всего Безыменского, Есенина и Жарова. Маяковского абсолютно не спрашивают. Из старых поэтов читают Пушкина, Некрасова, Никитина и немного Лермонтова... Демьяна Бедного не спрашивают» (3:57). Библиотека клуба при машиностроительном заводе им. Владимира Ильича сообщает, что «За последнее время начали просить стихи, - просят Пушкина, Лермонтова, Есенина, Некрасова, меньше Д. Бедного, Безыменского и Обрадовича» (3:57). Неутешительны данные Районной Замоскворецкой библиотеки им. Л. Н. Толстого: «Мало читают Д. Бедного, еще меньше Маяковского» (3:57). Наконец, Ник. Ларионов в очерке Книга в массе (Из поступивших писем) анализирует корреспонденцию журнала: по его свидетельству, читатели «...мелких рассказов и стихов не любят. Тяготеют к романам и повестям, чтобы «поволноваться с героями» (4:50).

Причины такой нелюбви просты и очевидны: «Маяковского, Пильняка, Лидина рабочий класс чуждается: пишут больно заковыристо и непонятно» (4:50). Военком тов. Т. Розен (Печерск Киевской губ.) прямо наставляет редакцию: «Побольше Безыменского, Жарова, Гладкова, Фурманова, Серафимовича. Несите их в массы, ибо провинция эти имена знает недостаточно» (4:51).

Неудивительно, что вкусовые пристрастия простых рабочих в целом почти совпадают с представителями советской элиты. Так, товарищ Н. Давыдов (председатель фабзавкома машиностроительного завода 
имени Владимира Ильича) жалуется на непонятность Маяковского («не понимаю я и Маяковского» (2:35), а начальник Центрального статистического управления, большевик с подпольным стажем и в недавнем прошлом оппозиционер-троцкист Н. Осинский ${ }^{23}$, выделивший из всего потока современной литературы лишь Цемент Ф. Гладкова (прозаическое произведение, бесспорно лидирующее в читательских предпочтениях опрошенных), рассуждает об отсутствии достаточного интереса к современной литературе: «Общим недостатком нашей литературы является ее темный и запутанный язык и ее фокусничество в стиле и в построении произведений. Это печальное наследие буржуазных символизма и футуризма не отброшено даже и пролетарскими писателями» (1:51). Те же из опрашиваемых, чей уровень культуры достаточно велик, довольствуются своими запасами дореволюционных времен: так, знаменитый врач-офтальмолог М. И. Авербах (среди прочих лечивший Ленина) заявляет, что его чтение - Анатоль Франс и Достоевский (2:34).

Такие предпочтения, как и неприятия, заставляют вновь вернуться к позициям Пастернака и Асеева. Из материалов «налитпостовцев» совершенно очевидно, что современная советская поэзия, вопреки стараниям ее адептов, так и не стала массовой. Потребность в «лирике» удовлетворяется поэтами-классиками, а также Есениным, остальные же упомянутые авторы в большинстве своем относятся к отряду «комсомольских» и «пролетарских» поэтов и известны широкому читателю, скорее всего, благодаря публикации их произведений в партийной периодике в качестве текстов мобилизационно-пропагандистского характеpa (упоминание Комсомолии и Груза Безыменского тут показательно). Видимо, следует учитывать и то, что в учебную литературу тех лет в основном попадала именно такого рода поэзия: так, в пособии Родной язык второй ступени П. О. Афанасьева, Н. Л. Бродского и Н. П. Сидорова, к 1930 году выдержавшему уже 7 переизданий (Афанасьев и др. 1930), в разделе «Искусство и классы» (следующим за разделом «Эпоха трех революций (1905-1917)») современная поэзия представлена именами все тех же пролетарских поэтов - А. Жарова, В. Казина, В. Кириллова, а также Д. Бедным и П. Орешиным (его стихотворением Пролетарским поэтам). Иначе говоря, система образования, так же, как и сейчас, вовсе не формировала вкус начинающего читателя к современной поэзии, отбирая авторов и тексты по идеологическому, а не эстетическому принципу. Впрочем, причины популярности Жарова или Безыменского у массовой аудитории заключались не только в том, что эти имена насаждались, используя выражение Б. Пастернака по другому поводу, «как картофель при Екатерине», но и общим невысоким уровнем читательской культуры рабоче-крестьянской аудитории, да и многих представителей новой, советской элиты.

\footnotetext{
${ }^{23}$ Настоящее имя - Валериан Оболенский.
} 
Пастернак трезво оценивал как разобщенность и социальную маргинальность прежних читателей лирики, так и невысокий уровень культурных запросов и вкусов нарождающихся новых, почему и диагностировал упадок поэзии: для нее должен сперва возникнуть в будущем новый читатель и новый, соответствующий ему автор. Асеев же, исходя из футуристического убеждения в наступлении будущего уже сегодня, готов был бороться за нынешнего читателя, поэтому в партийной газете публикует обзор современной поэзии, напоминающий отчасти донос, и в нем не слишком убедительно пытается связать два конца читательских предпочтений - лирику Есенина и пропагандистское стихотворчество «комсомольских поэтов», якобы на пару отвращающих пролетариат от истинной поэзии, которая способна совмещать революционную боевитость и оптимизм с формальною отточенностью стиха - поэзии подлинно левой - лефовско-конструктивистской. Увы! - его усилий для этого явно было недостаточно: стоит только посмотреть разделы рецензий ведущих литературных журналов тех лет, чтобы убедиться, что асеевский порыв был мало кем поддержан. Так, в «Новом мире» из 90 рецензий, напечатанных в 12 номерах журнала за 1926 год, стихотворным книгам посвящено всего 4 рецензии (коллективный сборник поэтов Сибири Вьюжные дни; Малиновая шаль И. Грузинова; Лениниана. Фрагменты поэмы Г. Санникова и Солнечная юность М. Юрина); в «Красной нови» из 89 рецензий поэтическим изданиям посвящено 7 (из них по 2 - на собрание сочинений Есенина и на Повесть о рыжем Мотэле И. Уткина). Поэтому остается только согласиться с оценкой Бориса Пастернака - 1926 год не был благоприятным для развития отечественной поэзии.

\section{References}

Aseev, Nikolay. “Novye pesni”. Novy mir. № 10 (1926): 150-158.

Aseev, Nikolay. "Poeziya v 1926 godu”. Leningradskaya pravda, 28.10 (1926): 5.

Afanasyev, Petr O., Brodskiy, Nikolay L., Sidorov, Nikolay P. Rodnoy yazyk vtoroy stupeni. Rabochaya kniga. 7 gruppa. Izd. 7-e, dop. Moskva: Rabotnik prosvescheniya, 1930.

Gornung, Lev. Vstrecha za vstrechey. Po dnevnikovym zapisyam. In: Pasternak, Boris. Polnoe sobranie sochineniy s prilozheniyami. V 11-ti tt. Vol. XI. Boris Pasternak v vospominaniyakh sovremennikov. Moskva: Slovo, 2005: 70-84.

Mandelshtam, Osip. Armiya poetov. In: Sobranie sochineniy: v 4-ekh tt. Vol. 2. Proza. Moskva: TERRA - TERRA, 1991: 208-216.

Mayakovskiy, Vladimir. “Kak delat stikhi?”. Leningradskaya pravda. 23.05 (1926): 3.

Mayakovskiy, Vladimir. “Kak delat stikhi?” In: Sochineniya: v dvukh tt. Vol. 2. Poemy. Pesy. Proza. Moskva: Pravda, 1988: 664-697.

Na literaturnom postu. № 1-8 (1926).

Pasternak. Boris. Otvet na anketu "Leningradskoy pravdy". In: Sobranie sochineniy: v pyati tt. Vol. IV. Moskva: Khudozhestvennaya literatura, 1991: 619-620.

Pasternak, Boris. Polnoe sobranie sochineniy s prilozheniyami: v 11-ti tt. Vol. V. Moskva: Slovo, 2004: 213-214.

Tynyanov, Yuriy. Promezhutok. In: Literaturny fakt. Moskva: Vysshaya shkola, 1993: 264-291. 